WATER BORNE COATING BASED ON NEW NANO-COPOLYMERS(STYRENE/ 2- ETHYL HEXYL ACRYLATE).

\author{
H. Abd El-Wahab ${ }^{1}$, M. Attia ${ }^{2}$, W.A. Hassan ${ }^{3}$, A. M. Nasser ${ }^{1}$ \\ 1) Chemistry Department, Faculty of Science, Al-Azhar University, Cairo, Egypt. \\ 2) Chemist at El Nada Company for paints, 5th settlement, Egypt. \\ 3) Polymer Department Manager, Egyptian British Company for polymers and chemicals, 6th of \\ October, Egypt. \\ Corresponding author. H. Abdel Wahab, hamada19982000@ hotmail.com phon: +201096249381
}

\begin{abstract}
Nanoemulsion copolymers are stable liquid-in-liquid dispersions. Smaller particle sizes tend to valuable properties such as high surface area per unit volume, gloss, washablity, viscosity, and stability. So, new nanostyrene acrylate copolymers based on 2- Ethyl Hexyl Acrylate monomer by using Two different surfactants were prepared by emulsion polymerization, and formulated as a binder for water based paints to get useful properties. These nanoemulsion copolymers also confirmed by IR, GPC, DSC, TGA, TEM and zeta potential. The prepared nano copolymer showed enhancement in solid content, viscosity, and suitable glass transition temperature for coating formula. Finally, based on the results we compared between the prepared nano copolymers as a binder with the commercial styrene acrylate copolymer. The results obtained indicated that the prepared nanocopolymers can be used as a good binder for paints to improve all the film properties and mechanical properties of paints
\end{abstract}

Keywords: 2-ethyl hexyl acrylate, styrene acrylate, nanoemulsion copolymers, water borne coating.

\section{1- INTRODUCTION}

Research into waterborne coatings is fast growing because of environmental concerns over the volatile organic components present in traditional solvent based paints [1,2]. Waterborne latex coatings contain polymer particles which are dispersed in an aqueous medium. Latex nanocomposites are an advanced class of latex coatings containing polymer during the last decades, water-based acrylic coatings have been widely used as industrial coatings [3]. Acrylic copolymer nanoemulsions were prepared based on methyl methacrylate (MMA) and butyl acrylate (BA). The prepared polymers were used as pretanning of the depickled hide to enhance the physico-mechanical properties of tanned leather , the hardness and flexibility of the copolymer is a function of the composition of the monomer. In general, acrylic ester copolymer nanoemulsion is of immense importance for industrial applications [4]. The polymer emulsion of styrene and acrylates monomers shows advantages in, weather resistance, stain resistance, gloss and color retention resistance.
Also, the film compactness from the styreneacrylic emulsion can be improved by decrease the particle size of emulsion copolymer to get useful properties in coating application, the formation of polymer particles takes place by entrapment of radicals in micelles (micellar nucleation), precipitation of growing oligomers in the continuous phase (homogeneous nucleation entrapment of radicals in monomer droplets (droplet nucleation) [5,6]. In the case of micellar nucleation, the micelles compete with monomer droplets in capturing free radicals because of their relatively large surface area [7]. Butyl acrylate-styrene (BA/ST) nanoparticles were prepared by various methods such ultrasonic emulsifier-free emulsion polymerization [8]. Most commercial latexes are copolymers designed by the simultaneous copolymerization of two or more monomers. The eventual latex properties are determined the copolymer composition, molecular weight distribution and particle morphology. To control these properties, many operative variables can be used (temperature, initiator, and co monomer (s)types and 
concentration. In view of that, acrylic acid was added to modify styrene acrylate copolymer during latex synthesis. [9], semi continuous emulsion polymerization, hetero- Phase polymerization with reactive surfactants or by non-seeded semi-batch emulsion polymerization were carried out with different applications for this type of copolymers [1012]. This work is designed to prepare $\mathrm{St} / 2$-EHA binders to be introduced in coating applications. The obtained results from the properties of the coated films for the formulation based on the new nano copolymers as a binder were compared with the properties of the coated films for formulation based on the commercial binder (Arakril ADC 750) as shown in the manuscript.

\section{EXPERIMENTAL}

\subsection{Materials}

Styrene (ST), 2-Ethyl Hexyl Acrylat (2EHA) acrylic acid (AA) and acrylamide (AAm) monomers, products from Elf Chem. (ATO) Company France. Potassium per sulfate "KPS", laboratory grade chemicals, texapon "SLES" were purchased from Sigma-Aldrich Germany and were used as received. Nonyl phenol ethylated (NP30) from DOW company. Desponil LDPS 25 from BASF SE Germany. Ammonium hydroxide and sodium acetate for $\mathrm{pH}$ control and regulation, respectively, were obtained from El-Nasr for Chemical Industries. Titanium dioxide Kronos 2300 From KRONOS TITAN GmbH.

\subsection{Methods and techniques}

\subsubsection{Pre-emulsion preparation}

Distilled water, ionic surfactant, Styreen, 2 ethyl hexyl acrylate, and acrylic acid monomers were added into a glass beaker equipped with stirrer at $1000 \mathrm{rpm}$ for $30 \mathrm{~min}$. to finally obtain a homogenous pre-emulsion.

\subsubsection{Polymerization procedure}

Semi-batch or semi-continuous emulsion polymerization was carried out using a $1 \mathrm{~L}$ stainless steel reactor equipped with a reflux condenser, stainless steel stirrer (Heidolph Gmbh.), and 2 feed streams separated. The first feed stream was a mixture of (pre-emulsion ). The other feed was the initiator solution. Before emulsion polymerization was started-up, the reaction Vessel was initially charged with the desired amount of water, another part NP30 as non-ionic surfactant, Sod. Acetate as a buffer, in this sequence. The reaction temperature was maintained at $80^{\circ} \mathrm{C}$ during the polymerization and stirring the reaction mixture at a rate of 150 rpm. After $5 \mathrm{~min}, 5 \%$ of the pre-emulsion mixture total amount was added over $15 \mathrm{~min}$ (Seed reaction). And amount of initiator solution, acrylamide monomer was added to the remainder part of pre-emulsion under the stirrering for 5 min., the monomer mix (preemulsion) were slowly and continuously added and the remaining amount of the initiator aqueous solution, until reach to $4 \mathrm{~h}$, then keeping the reactor $1 \mathrm{~h}$ at $80^{\circ} \mathrm{C}$ to remove any free monomers, after that, the reactor was cooled to $30^{\circ} \mathrm{C}$ and the $\mathrm{pH}$ was adjusted to 8 with ammonia solution. After neutralization, the addition of biocide to the latex was carried out and filtered with a 100 mesh Filter and then collected, these polymerization procedure was formulated and represented as shown in table 2 and 3 by Two different surfactants (Texapon and NP30, Desponil LDPS 25 and NP30), the reaction represented by scheme 1 [11].

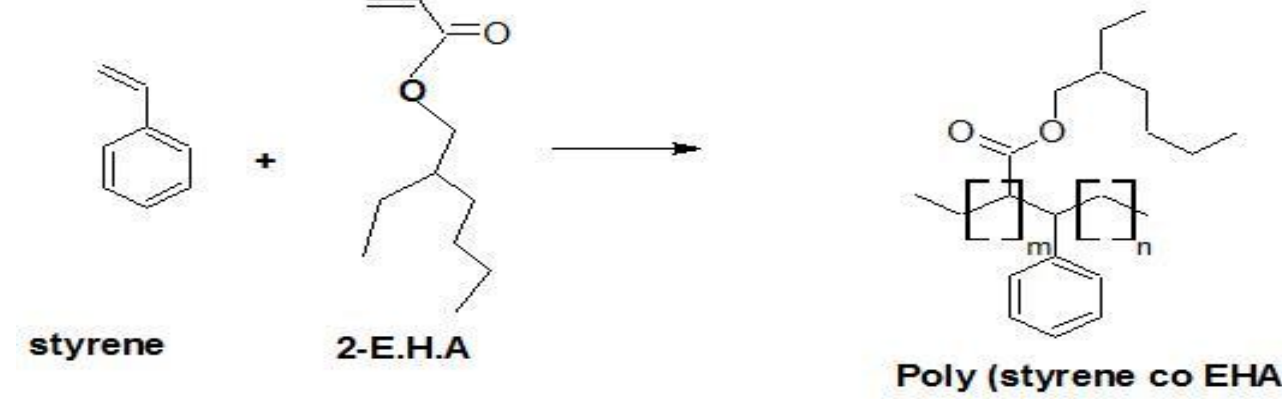

Scheme 1. Chemical structure of the prepared St/2EHA Nano emulsion copolymer. 
Table 1. Formulation of the prepared latexes using texapone as an anionic surfactant (polymer A).

\begin{tabular}{|l|c|c|}
\hline Component & Wt. $\%$ & Wt. (g) \\
\hline Styrene & 31.6 & 316 \\
\hline 2-EHA & 18.4 & 184 \\
\hline A.A & 2 & 20 \\
\hline A.A.m & 0.1 & 11 \\
\hline Texapon & 2.2 & 4 \\
\hline NP30 & 0.4 & 1 \\
\hline Sod.Acetate & 0.1 & 1 \\
\hline antifoam & 0.1 & 3 \\
\hline KPS & 0.3 & 459 \\
\hline Dist. water & 45.9 & 80 \\
\hline \multicolumn{2}{|c|}{ SPECIFICATION } \\
\hline Temp. ${ }^{\circ}$ C & \multicolumn{2}{|c|}{12000} \\
\hline $\begin{array}{l}\text { Solid } \\
\text { Content }\end{array}$ & $96 \%$ \\
\hline Coagulum & $0.3 \%$ \\
\hline $\begin{array}{l}\text { Addition } \\
\text { time }\end{array}$ & $31 \%$ \\
\hline Viscosity cp & $\begin{array}{l}\text { Gravimetric } \\
\text { Converting }\end{array}$ & \\
\hline
\end{tabular}

Table 2. Formulation of the prepared latexes using Desponil LDBS 25 as an anionic surfactant (polymer B).

\begin{tabular}{|l|c|c|}
\hline Component & Wt. \% & Wt. (g) \\
\hline Styrene & 31.6 & 316 \\
\hline 2-EHA & 18.4 & 184 \\
\hline A.A & 2 & 20 \\
\hline A.A..m & 0.1 & 1 \\
\hline Desponil LDPS 25 & 2.5 & 25 \\
\hline NP30 & 0.4 & 4 \\
\hline Sod.Acetate & 0.1 & 1 \\
\hline Anti foam & 0.1 & 1 \\
\hline KPS & 0.3 & 3 \\
\hline Dist. water & 44.5 & 445 \\
\hline \multicolumn{2}{|c|}{$51.5 \%$} \\
\hline Temp. ${ }^{\circ}$ & SPECIFICATION & 80 \\
\hline Solid Content & \multicolumn{2}{|c|}{$97.5 \%$} \\
\hline Coagulum & $0.15 \%$ & 1.5 \\
\hline Addition time & \multicolumn{2}{|c|}{} \\
\hline Viscosity cp & $\begin{array}{l}|c| \\
\text { Gravimetric }\end{array}$ & \multicolumn{2}{|c|}{} \\
\hline
\end{tabular}

2.3. Characteristics of prepared nanostyrene- ethyl hexyl acrylate copolymers.

\subsubsection{Fourier transform infrared (FTIR)}

The copolymer composition of dried samples was proved by FTIR spectra using JASCO FTIR 6100 in the range of $4000-400$ $\mathrm{cm}^{-1}$ using $\mathrm{KBr}$ pellets. FTIR was also used to examine the functional group of the prepared samples.

\subsubsection{Transmission electron microscopy (TEM)}

The morphology of the copolymer particles was examined using transmission electron microscopy. In TEM the dry sample has to be transferred into ultra-high vacuum and is illuminated by a high energy Beam of electrons (for example100 keV) In an ideal case, a lateral resolution of around $1 \mathrm{~nm}$ is achievable. To perform TEM analysis, the latex was diluted with distilled water, a drop of the diluted latex was placed on a carbon - coated grid and dried in a dissector, then, $1-2$ drops of a $0.8 \mathrm{wt}$. $\%$ aqueous solution of phosphor tungstic acid (PTA) was used to stain the particles.

\subsubsection{Thermo gravimetric analysis (TGA)}

$T G A$ analysis was performed using Shimadzu TGA - 50 thermo gravimetric analyzer, Columbia, EUA, in a nitrogen atmosphere at a heating rate of $10{ }^{\circ} \mathrm{C} / \mathrm{min}$ in the range between room temperature and $600^{\circ} \mathrm{C}$.

\subsubsection{Differential scanning calorimetric analysis (DSC).}

$\mathrm{Tg}$ of each copolymer sample was measured using a Differential scanning calorimetric analysis.

DSC analysis was carried out by Shimadzu DSC-60 differential scanning calorimeter Columbia, EUA. All samples were heated with a scan rate of $10^{\circ} \mathrm{C} / \mathrm{min}$ over a temperature range of -60 to $110^{\circ} \mathrm{C}$ in nitrogen atmosphere. 


\subsubsection{Gel permeation chromatography (GPC)}

The weight-average $(\mathrm{Mw})$, and numberaverage (Mn) molecular weights, were determined using Agilent 1100 series gel permeation chromatography (GPC), Germany, equipped with G1362A refractive index detector with 100-104-105 $\mathrm{A}^{\circ}$ ultra styragel columns. Polystyrene was used as a standard. THF was used as an eluent with a flow rate of

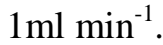

\subsubsection{Dynamic light scattering}

The particle size and particle size distribution of the prepared copolymer were determined by dynamic light scattering, using Malvern Zeta sizer Nano, UK. This instrument was used to measure the hydrodynamic size in the range of $0.4-10000 \mathrm{~nm}$. The number of single measurements of particle size was calculated as the average of three experimental determinations. The same instrument was used to measure the zeta potential values of the prepared copolymers in the range of -200 to $+200 \mathrm{mV}$.

\subsubsection{Viscosity measurement}

The viscosity of the prepared copolymers samples was measured using a digital viscometer manufactured by Sheen Company, used it in measure of paint formula. For all the emulsions, the viscosity was measured using BrookfieldRVDVE-II+Pro Viscometer . The test was performed at room temperature and different spindles were used depending on the viscosity of emulsions, where spindle number 2 was used for the emulsions of lowest viscosities and spindle number 7 for the highest viscosities.

\subsubsection{Gloss Test of Paint Samples of Prepared Latex.}

Paint samples were applied on glass panels using SIMIX film applicator and let it to dry for $48 \mathrm{~h}$ before doing the gloss test using minigloss $60^{\circ}$ gloss-meter manufactured by Sheen company.

\subsubsection{Wet Scrub Resistance (Washablity) Test}

Compared with a Commercial Type, apply the paint sample to be tested on clean glass panels or other specific substrate (PP sheet) of suitable dimensions $(150 \mu \mathrm{m})$ using SIMEX film applicator. Let it dry for one day, then one week before doing the washablity test. Put the painted panel into the wet abrasion scrub tester REF 903 (washablity tester) and apply the test according to (ASTM D 2486).

\subsubsection{Dry film hardness measurement}

The scratch hardness of the prepared polymers dry films was estimated by pencil hardness test. The test procedure was done using Sheen Pencil Hardness Kit accompanied with a set of calibrated wood pencils with scale of hardness $6 \mathrm{~B}$ (softest) to $6 \mathrm{H}$ (hardest).

\subsubsection{Dry film adhesion measurement}

The cross-cut test is a method for determining the resistance of paints and coatings to separation from substrates, utilizing a tool to cut a right angle lattice pattern into the coating, penetrating all the way to the substrate. The cross-cut test instrument used was manufactured by Sheen Company.

\section{RESULT AND DISCUSSION}

3.1. Characteristics of the prepared nanocopolymers.

\subsubsection{IR spectroscopy of the prepared nanocopolymer.}

In order to explain the copolymer composition, FTIR was performed for copolymers as an arbitrary copolymer and for the emulsifier system (Texapon and NP30) as shown in Fig. 1.A and B.

The spectrum data signifies the following bands: the aromatic $\mathrm{C}-\mathrm{H}$ stretching frequencies at $3030 \mathrm{~cm}^{-1}, 3063 \mathrm{~cm}^{-1}, 3086 \mathrm{~cm}^{-1}$ and 3104 $\mathrm{cm}^{-1}$ concerning styrene ring. The value of the carbonyl stretching frequency is $1727 \mathrm{~cm}^{-1}$. The bands at 1638 , and $1450 \mathrm{~cm}^{-1}$ can be assigned as the ring stretching modes of styrene. The band at $751 \mathrm{~cm}^{-1}$ is due to the out of the plane $\mathrm{C}-\mathrm{H}$ bonding mode of the mono substituted benzene. $\mathrm{C}-\mathrm{H}$ out of plane deformation occurs at 3060 and at $1638 \mathrm{~cm}^{-1}$ [11]. 


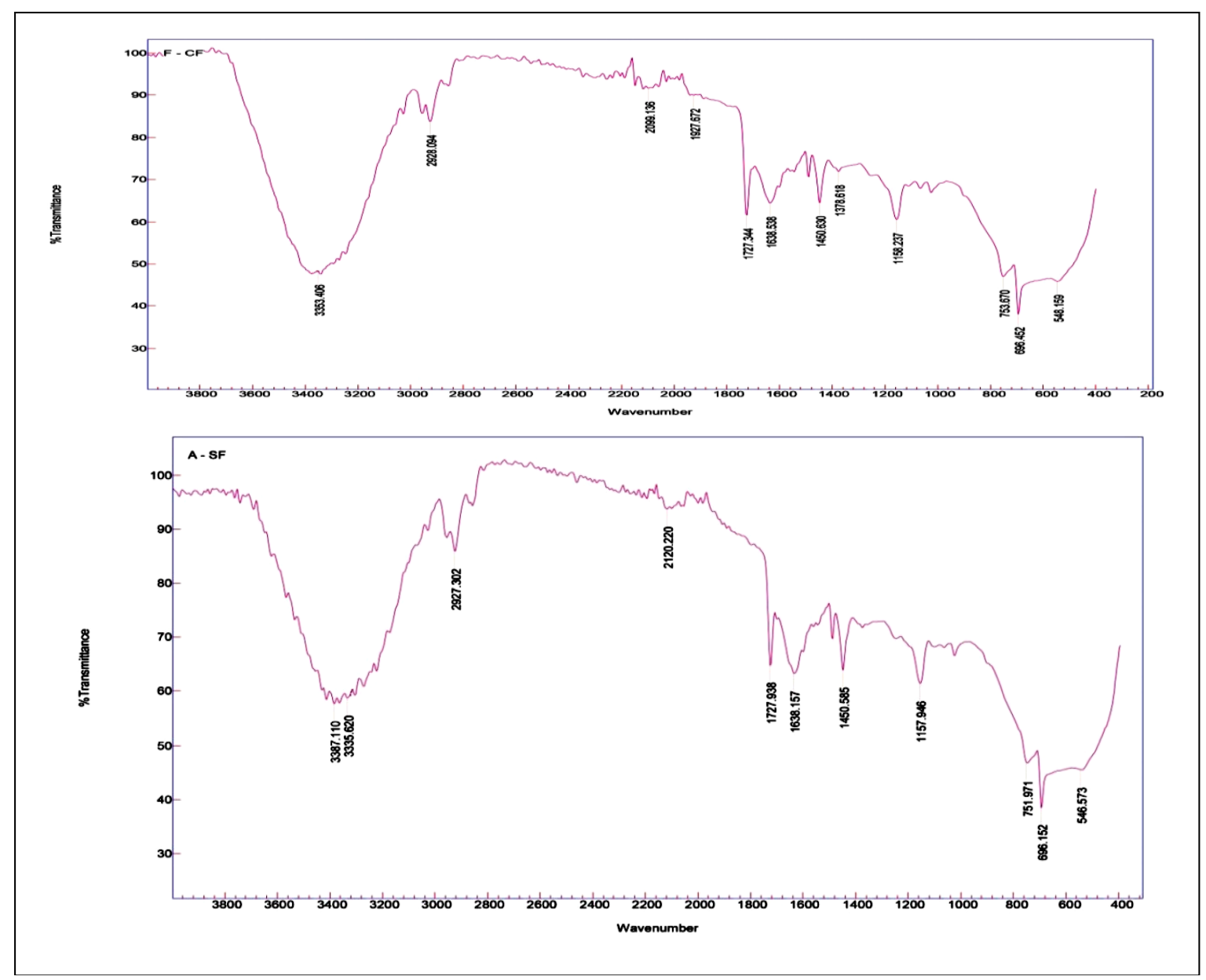

Fig.1. FTIR spectra of Latex A using (Texapon and NP30), and FTIR spectra of Latex B using (LDPS 25 and NP30).

Also, several characteristic bands of both styrene and acrylic acid are present. The band at $1727 \mathrm{~cm}-1$ is characteristic of the nonbonded and hydrogen-bonded carbonyl groups in acrylic acid segments of the copolymer, respectively. The band at $2927 \mathrm{~cm}-1$ is specific of aliphatic hydrocarbon group of 2-ethyl hexyl acrylat. The ionization of acrylic acid due to the presence of a neutralizing agent, the presence of the intense peaks at $3335,1727,1450$ and $1157 \mathrm{~cm}-1$ corresponding to N-H stretching, $\mathrm{C}=\mathrm{O}$ stretching and $\mathrm{C}-\mathrm{N}$ stretching due to acrylamide group, respectively.

\subsubsection{Molecular weight.}

The characteristics of acrylic resinscoatings are generally associated with the molecular weight and the co-monomer ratio. Also, toughness, abrasion resistance, or impact resistance of the final coatings can be enhanced with the escalation of the molecular weight of polymers. Nonetheless, the incorporation of a co-monomer usually modifies the glasstransition temperature $(T g)$ and the molecular weight and that's why the mechanical properties of the final product can be improved [13].

Reaction property originates from the participation of the propagating radicals, which diminishes the termination rate [14]. The Molecular weight obtained by GPC for the two different prepared copolymers are shown in Table 3 and Fig.3. A and B. 


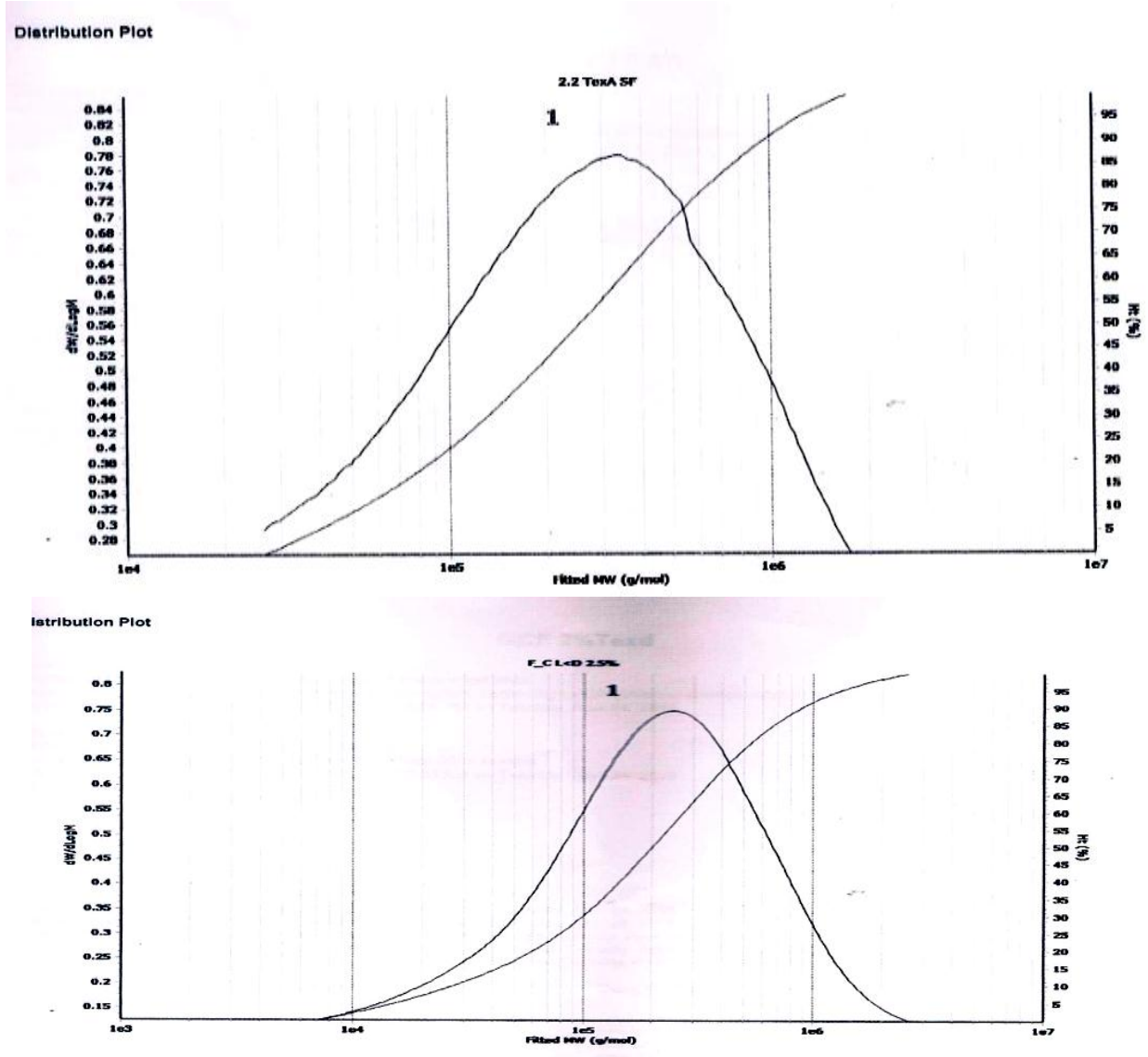

Fig.3. the molecular weight of the prepared Latex A using (texapone and NP30), and the molecular weight of the prepared Latex B using (Desponil LDPS 25 and NP30).

\begin{tabular}{|c|c|c|}
\hline Formula & A & B \\
\hline Mn $\mathrm{g} / \mathrm{mol}$ & 137948 & 73666 \\
\hline MW $\mathrm{g} / \mathrm{mol}$ & 386855 & 356942 \\
\hline
\end{tabular}

Table 3. The molecular weight of the prepared copolymers (polymer $\mathrm{A}$ and $\mathrm{B}$ ) as measured by GPC.

\subsubsection{Thermal analysis of the prepared copolymers.}

To appreciate the importance of these prepared copolymers for water based coatings, glass transition temperature" $T g$ "should be in range $(20-45)^{\circ} \mathrm{C}$. Thus, $T g$ is important in describing the properties and potential end use of a polymer. The DSC thermo grams for some formulations are represented in (Fig.4. A and B). Fortunately, all formula had workable and suitable $\mathrm{Tg}$ for water based coatings applications, as shown in Table $4(\mathbf{C})$ and (Figure 4. A and B). Also thermo gravimetric analysis (TGA) is highly suggested for the optimization of process parameters. The threshed decomposition temperature provides a sign of the highest temperature that can be utilized for processing. The TGA curves of the copolymer samples are shown in (Fig.5. A and B) and the TGA data are also given in (Table 4. A and B). It is noticeably seen that the weight of the sample continuously decreases as the temperature increases. TGA data relating to the temperatures corresponding to $15 \%$ weight loss (T15), 50\% weight loss (T50), 90\% weight loss (T90) and maximum weight loss (T max) are the chief evidences of the thermal stability of the synthesized polymers. The relative thermal stability of the synthesized polymers has been evaluated by comparing the decomposition temperatures (Td) at different percentage weight loss. Higher values of T15, T50, T90 and Td indicate higher thermal stability of the polymeric systems [15]. Finally, all prepared polymers proved higher thermal stability due to the emulsifier system. 


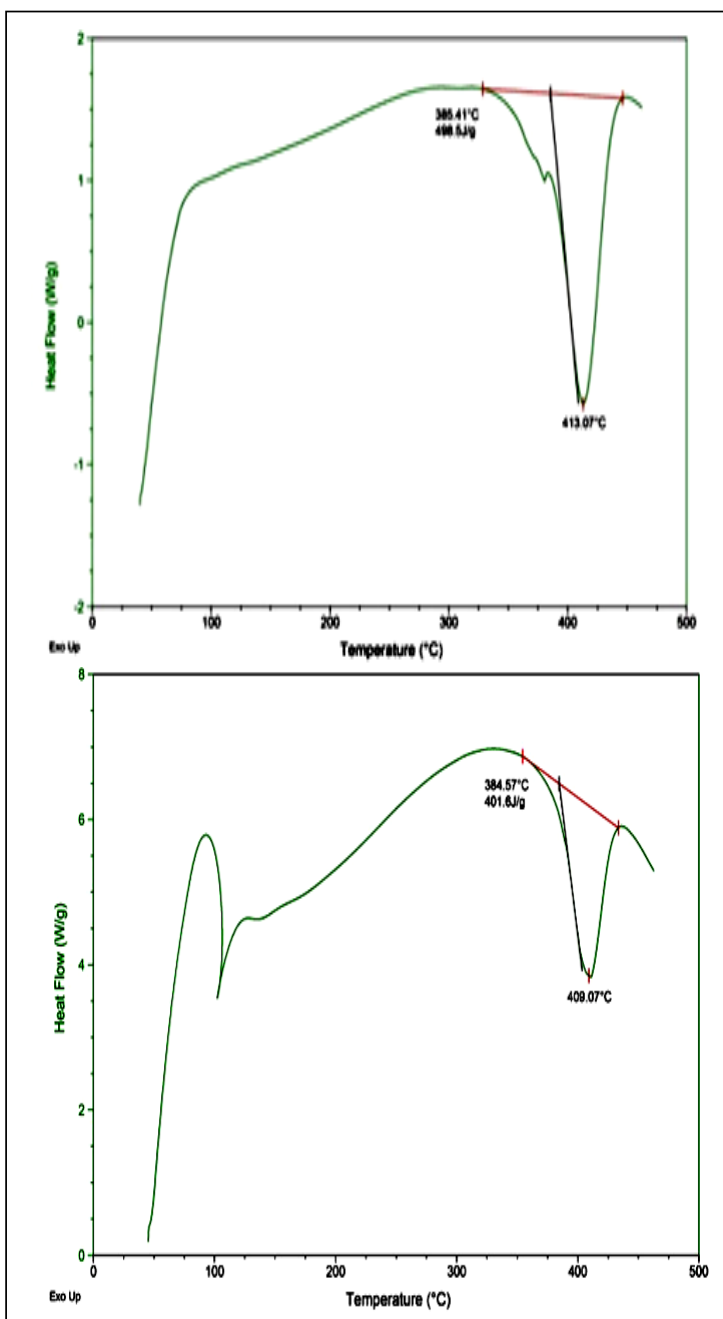

Fig.4. DSC curves for Latex A using (texapone and NP30), and DSC curves for Latex B using (Desponil LDPS 25 and NP30).

Table 4.A. TGA data of the prepared copolymer (polymer A and B).

\begin{tabular}{|l|c|c|c|c|}
\hline & \multicolumn{4}{|c|}{ Weight loss at various temperature } \\
\hline Run & 200 & 300 & 400 & $\max$ \\
\hline A & 1 & 1 & 37 & 93.8 \\
\hline B & 2 & 3 & 35 & 94 \\
\hline
\end{tabular}

Table 4.B. TGA data of the prepared copolymers (polymer A and B) and their $\mathbf{T g}$.

\begin{tabular}{|l|c|c|c|c|c|c|}
\hline & \multicolumn{5}{|c|}{ Temperature } \\
\hline $\begin{array}{c}\text { Decomposition } \\
\text { Temperature range } \\
\text { Td }\end{array}$ & $\begin{array}{c}\mathrm{T} \\
15\end{array}$ & $\begin{array}{c}\mathrm{T} \\
50\end{array}$ & $\begin{array}{c}\mathrm{T} \\
90\end{array}$ & $\begin{array}{c}\mathrm{T} \\
\max \end{array}$ & $T g$ \\
\hline $\mathrm{A}$ & $335-410$ & 385 & 410 & 423 & 394 & 32 \\
\hline $\mathrm{B}$ & $355-415$ & 380 & 405 & 415 & 390 & 32 \\
\hline
\end{tabular}
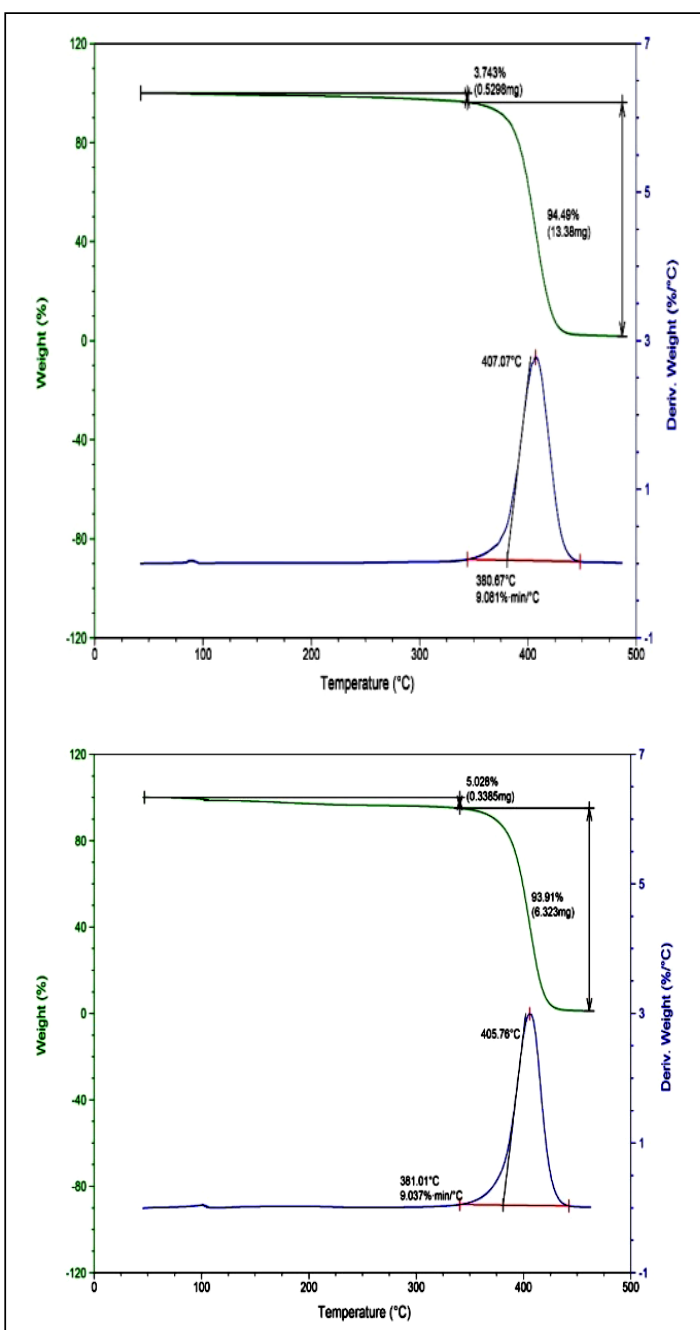

Fig.5. TGA curves for latex A using (texapone and NP30), and TGA curves for latex B using (Desponil LDPS 25 and NP30)

Table.4.C. DSC decomposition temperature of the prepared copolymers (polymer A and B).

\begin{tabular}{|l|c|c|c|}
\hline Run & $\begin{array}{c}\text { Initiation } \\
\text { temperature } \\
{ }^{\circ} \mathrm{C}\end{array}$ & $\begin{array}{c}\text { peak } \\
\text { temperature } \\
{ }^{\circ} \mathrm{C}\end{array}$ & $\begin{array}{c}\text { final } \\
\text { temperature } \\
{ }^{\circ} \mathrm{C}\end{array}$ \\
\hline $\mathrm{A}$ & 385 & 413 & 440 \\
\hline $\mathrm{B}$ & 384 & 409 & 425 \\
\hline
\end{tabular}

\subsubsection{Morphology of the polymer.}

The determination of mean particle size and particle size distribution in emulsion polymer latex is very important as they affect other properties of the latex (e.g., stability, rheology, optical, and electrical). It is important to mention that with increasing the mean particle size of the latex, the colloidal stability will decrease [16]. Luo and Zhou [17] explain 
the Nano encapsulation of hydrophobic monomers using mini emulsion that both thermodynamic (amount and type of surfactant, and hydrophilic monomer/hydrophobic monomer ratio) and kinetic (amounts of crosslinking or chain transfer agent) factors have a great impact on the latex morphology. Also, increasing the hydrophobicity of the polymer chains should prefer the encapsulation of the hydrophobic monomers. The TEM images of the particles with changing emulsifier system from (Texapone to Desponil LDBS 25) can be observed and it rearranges them to thermodynamically stable morphology. Also, it is clear that from the uniform particle size, that very low coagulation occurred during the polymerization reaction [18]. In this work, the second stage monomers "acrylic acid and acrylamide" were polymerized in presence of the core seeded latex. The latter can either be formed in dead seeding or in situ during the emulsion polymerization i.e., live seeding [17, 19]. TEM micrographs are shown in Figure 6 (a and b), respectively. It can be shown that a slight difference in contrast between the outer and inner portion of the particle. The TEM images of the core-shell particles with changing emulsifier system from [Texapone and NP30] to [Desponil LDPS 251 and NP30] can be observed. Also TEM images showed that the diameters of most particles were between 70$140 \mathrm{~nm}$ with narrow particle size.

A

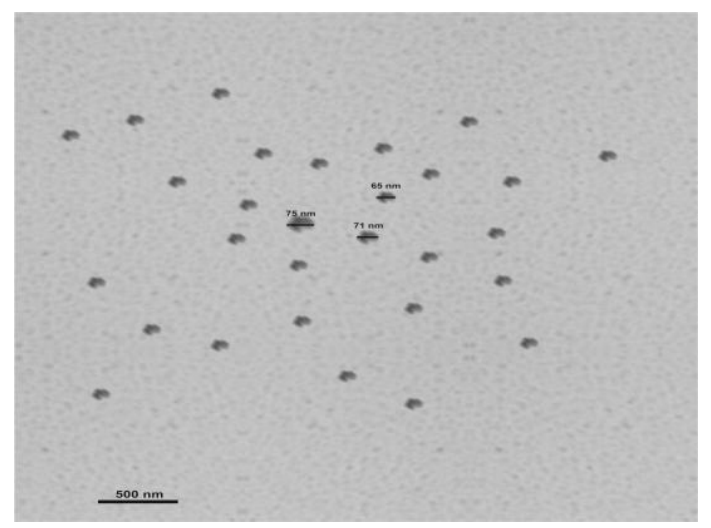

\subsubsection{Zeta potential}

Normally, emulsions that have zeta potentials higher than $+30 \mathrm{mV}$ or lower than $30 \mathrm{mV}$ are considered stable [20]. Therefore, it can be considered that all prepared emulsions had good stability fortunately; increasing zeta potential is a driving force to prevent particles from stacking; leading to the creation of nano scale stable particles and by inspection of Table 5 and Fig. 7 (A and B) for Particle size distribution for latex. Increasing of emulsification system concentration enhanced the stability with respect to the measured zeta potential. The number of micelles increased with the increasing surfactant content, there for more sites for polymerization occurred and smaller particle size of latexes formed. The surfactant was useful to control the particle size of latexes [21].

Table 5. Zeta potential of the prepared copolymers (polymer A and B)

\begin{tabular}{|c|c|}
\hline \multicolumn{2}{|c|}{ Zeta potential (mv) } \\
\hline A. Latex & B. Latex \\
\hline-37 & -52 \\
\hline
\end{tabular}

\subsubsection{Adhesion and hardness.}

The physical properties of latex polymer film, such as hardness and adhesion, are very important criteria to determine its practical application. These physical properties are

B

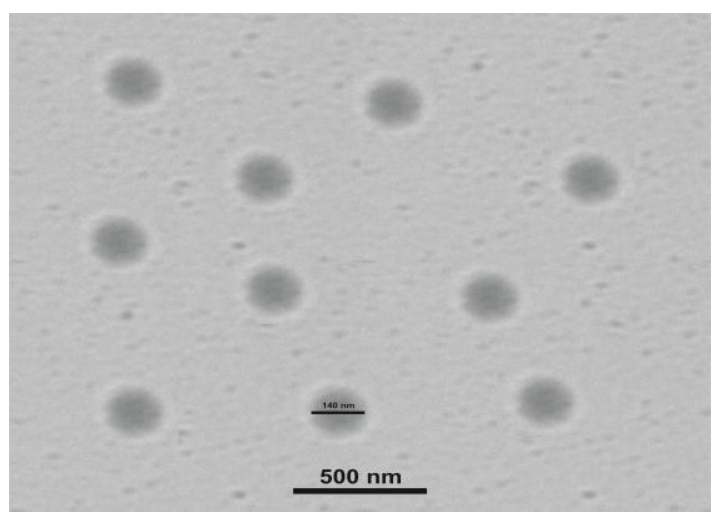

Fig.6 . TEM image for latex A average $(140 \mathrm{~nm})$, and TEM image for latex $B$ average $(70 \mathrm{~nm})$. 


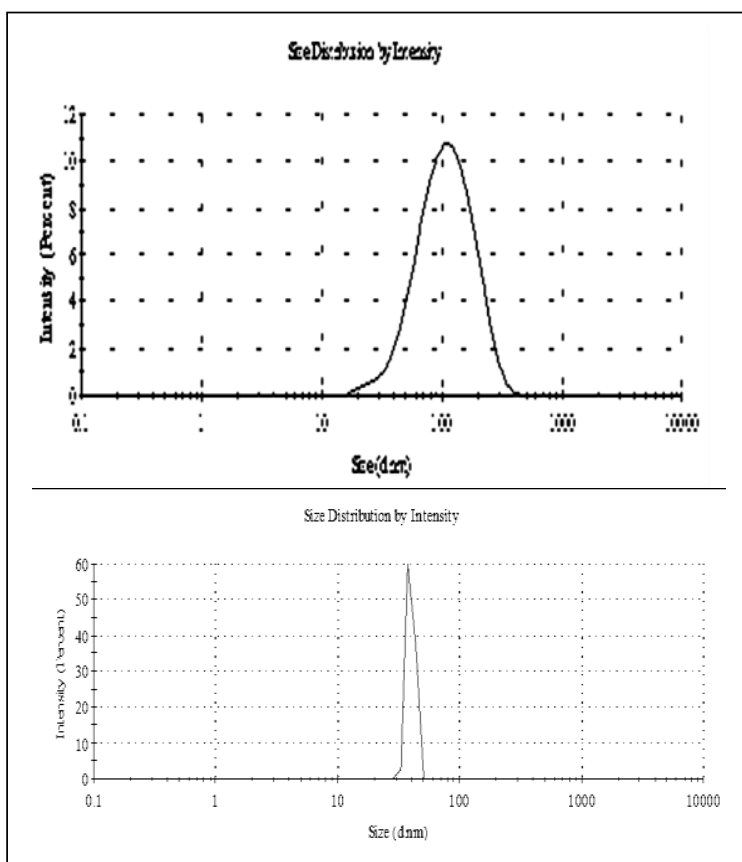

Fig.7. Particle size distribution for latex A using (texapone and NP30) and Particle size distribution for latex B using (Desponil LDPS 25 and NP30)

closely depending on macromolecular structure, the molecular weight, the size and morphology of the latex particles [22]. Dry film hardness is the ability to resist permanent indentation, scratching, cutting and penetration by hard object [23]. It can be observed that hardness and adhesion value were correlated and improved with the reduction in particle size which is dependent on the type and concentration irrespective of the emulsifiers system used and these showed as the results which represented in Table 6. D, the largest particles size imported some inherent weakness to the strength property. A possible explanation for the positive effect of smaller particles on adhesion and hardness values relates to the ability of these smaller particles to pack more tightly together during the drying process [26]. Thus increasing the area of contact between the polymer and the substrate.

Table.6. hardness and adhesion to the prepared copolymers (polymer A and B).

\begin{tabular}{|c|c|c|}
\hline test ${ }^{\text {Lattice }}$ & A & B \\
\hline Hardness & $\mathrm{H}$ & HB \\
\hline Adhesion & $2 \mathrm{~B}$ & 4B \\
\hline
\end{tabular}

\subsubsection{Colloidal stability}

The colloidal stability of waterborne dispersions is a very important characteristic. It determines their safe storage period. Kan et al. [25] and Huang et al. [26] have reported that to certain extent coagulum appeared when polymerization methods were used and all the obtained latex were sensitive to the electrolyte such as $\mathrm{NaCl}$ and $\mathrm{CaCl}_{2}$. However, in the present work, no coagulum appeared for all the lattices and experimental results revealed that all prepared latex initially undergo stability forlyear and exhibited excellent performance in terms of shelf-life these showed in the table 7 as stability of the prepared copolymers against adding electrolytes after 24h. These shown in Table 7 (polymer A and B).

Table.7. stability of the prepared copolymers against adding electrolytes after $24 \mathrm{~h}$. (polymer A and $B$ ).

\begin{tabular}{|c|c|c|}
\hline test $\quad$ Lattice & $\bar{A}$ & B \\
\hline Hardness & $\mathrm{H}$ & $\mathrm{HB}$ \\
\hline Adhesion & $2 \mathrm{~B}$ & $4 \mathrm{~B}$ \\
\hline
\end{tabular}

\subsubsection{The electrolyte stability.}

There are important factors that affect the colloidal stability of polymer latex such as the concentration of electrolytes that comes from ingredients like the buffer solution, the initiator, and surfactants. Stability test was carried out by adding $0.5 \mathrm{~g}$ of different Concentration salts $\left(0.1 \mathrm{M} \mathrm{NaCl}, 0.5 \mathrm{M} \mathrm{NaCl}\right.$ and $\left.0.1 \mathrm{M} \mathrm{CaCl}_{2}\right)$ to 0.5 polymer latex [27]. Immediate flocculation or flocculation after certain time was observed visually. Stability of the emulsions against electrolytes are shown in Table 8. Based on these table, it is clear that all the latex are generally stable when adding salts such as $\mathrm{NaCl}$, and $\mathrm{CaCl}_{2}$, even up to their saturated concentrations. The good stability may be attributed to the small size of latex particles and the steric and electrostatic stability offered by synergistic effect of the non-ionic and anionic surfactants combination mixture. These results are in accordance with the results reported elsewhere [28]. 
Table. 8. Stability of the prepared copolymers against adding electrolytes after one week. (Polymer A and B).

\begin{tabular}{|c|c|c|c|}
\hline $\begin{array}{c}\text { Salts } \\
\text { Latex }\end{array}$ & $\begin{array}{c}0.1 \mathrm{M} \\
\mathrm{NaCl}\end{array}$ & $\begin{array}{c}0.5 \mathrm{M} \\
\mathrm{NaCl}\end{array}$ & $\begin{array}{c}0.1 \mathrm{M} \\
\mathrm{CaCl}_{2}\end{array}$ \\
\hline $\mathrm{A}$ & $\bullet$ & $\bullet$ & $\bullet$ \\
\hline $\mathrm{B}$ & $\sqrt{ }$ & $\sqrt{ }$ & $\bullet$ \\
\hline
\end{tabular}

\section{$\sqrt{ }$ Refer to stable on salt addition.}

\section{- Refer to Little coagulation on salt addition after certain time}

\subsubsection{The thaw-freezing stability.}

Freeze-thaw stabilization of lattices is of considerable practical importance due to the need to store and transport these lattices within cold countries during winter. When the temperature is decreased to a degree where the dispersion medium begins to freeze, a third phases (ice) forms when freezing occurs, the water volume available to the emulsion particles progressively decreases, consequently leading to entrapping of the latex particles between the growing crystals of solid dispersion medium. The latex particles are forced to be into contact with each other [29]. Stability of emulsions against freeze-thaw destabilization is displayed in Table 9. Based on these results in Table 9, the thaw-freezing stability of the prepared lattices is improved. This may be attributed to the use of Desponil LDPS 25 in conjunction with Texapon resulting in carboxylate Poly (Styrene Acrylate) latex, stable to freeze-thaw cycles, or copolymerization of small amounts of hydrophilic monomers such as acrylic acid which are expected to improve the freeze-thaw stability of the novel prepared lattices because these acidic groups may concentrate near latex particles surfaces preventing inter particle coagulation. That's why, 0.5 wt. $\%$ of acrylic acid (AA) at each formulation was used in the monomer feed and the final lattices were neutralized with ammonia to improve the freeze-thaw stability of the novel prepared lattices [30].
Table.9. Thaw-freezing stability of the prepared copolymers (polymer A and B).

\begin{tabular}{||l|c|}
\hline $\begin{array}{l}\text { Test } \\
\text { Latex }\end{array}$ & Thaw-freezing stability \\
\hline A4 & 3 cycles \\
\hline B & 5 cycles \\
\hline
\end{tabular}

\subsection{Effect of surfactant type and percentage on the latex physical properties.}

Emulsifiers have an important part to play in the manufacture of polymer dispersions, and they also have a substantial influence on the performance characteristics of the final formulated product. Polymer dispersions are typically used in the coatings industry, in papermaking and paper coating, in adhesives and in the textile, leather and construction industries. The properties of dispersions manufactured by emulsion polymerization are determined by the choice and mixtures of the various monomers, but these properties are also influenced to a large extent by the choice of emulsifiers and their quality. Emulsifiers play two decisive roles in polymerization processes. One is to stabilize the monomer droplets during the manufacturing process and the other is to stabilize the cured polymer particles in the finished latex. However, the main role of surfactants is to form the micelles that enable the polymerization processes to take place. Anionic emulsifiers form micelles with a spherical structure in aqueous solutions. The free-radical polymerization reaction takes place in these micelles, which take on the function of a "mini-reactor". The monomer reacts with the water-soluble initiator to form free radicals and diffuses into the micelles, where further chain propagation takes place. These were represented as in Fig. 8 in schematic diagram of reaction. The presence of a large number of emulsifier micelles in parallel creates a series of enclosed spaces in which the polymer particles gradually grow as the reaction progresses. Generally, the amount of emulsifier used in the polymerization process is sufficient to enable high-quality polymer dispersions to 

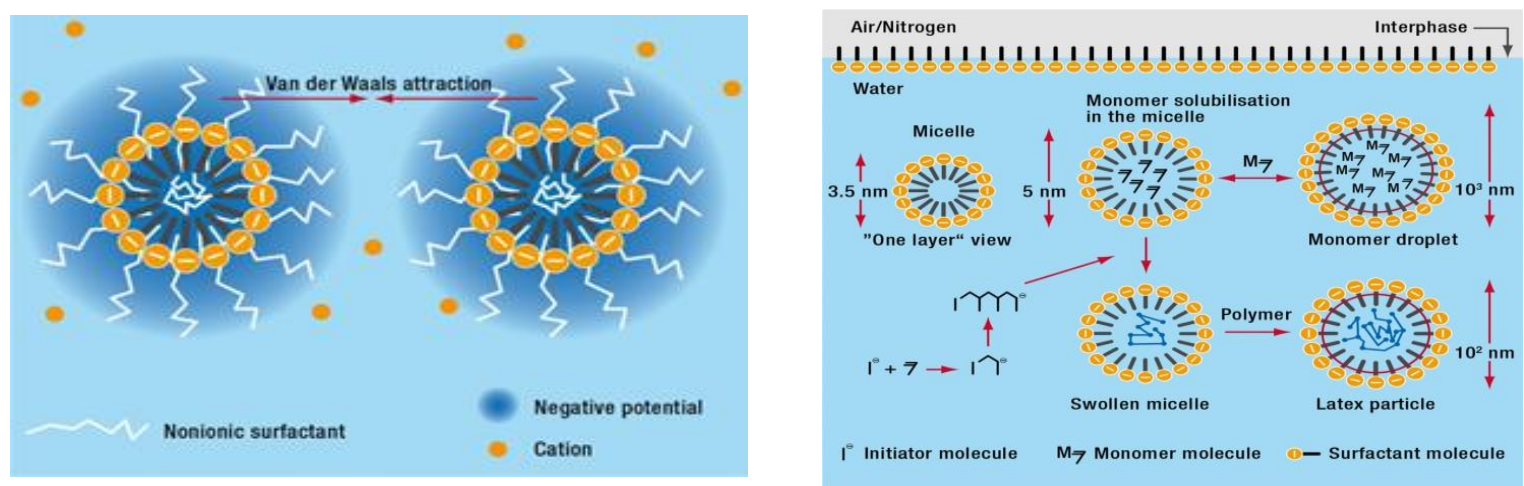

Fig.8 Schematic diagram of reaction between monomers and surfactants

be manufactured that do not contain any coagulated solids. However, it is possible that insufficient emulsifier is present to be able to form a saturated adsorbed layer on the surface of the particles the latex can be stabilized by means of electrostatic repulsion or steric hindrance between the polymers particles. Nonionic emulsifiers can also be added to polymer dispersions to improve their mechanical stability and their stability in the presence of electrolytes. The type of emulsifier, its consistency in quality and purity and its composition influence the formation and size of particles and the properties of the latex when it is applied.

\subsection{Solid content and coagulum.}

The solid content and coagulum of the prepared copolymers were determined gravimetrically and recorded in Table 1 and 2. To begin with, the solid content had somewhat constant value which can be attributed to the complete polymerization of the monomers that had constant molar ratio. It was found that solid content depends mainly on polymerization rate and reaction conditions and slightly on monomer composition. Low solid content values are usually referred to high percentage of coagulation of solid polymers during polymerization or the yield of the reactants which depends on the initiation, surfactant system and reactivity of the reactants. Coagulum is formed in several emulsion polymerizations, from the smallest laboratory scale to the maximum production reactors. It is detected in many forms, from a single lump of polymer with little or no fluid latex to tiny sand like grains suspended in a stable latex. Typically, it is found as lumps in the latex or deposited on the container surfaces. The polymer system and the polymerization recipe and technique affect the type and amount of coagulum produced. Two mechanisms are proposed for the formation of coagulum: (i) latex instability which triggers flocculation and growing of the aggregates to macroscopic size; (ii) an altered polymerization mechanism, e.g., polymerization in large monomer drops or a distinct monomer layer in the vapor space above the latex and the reactor surfaces [31]. The low coagulum values may designate that the primary particles were well protected by surfactant molecules from the beginning of polymerization. Particle accumulation, if any, was very restricted. It is worth mentioning that high solid content $50 \%$ and low coagulum were the main request in production of styrene acrylate emulsion on a large scale for industrial applications [32].

4. Application and evaluation of the emulsion paints formulation based on the prepared nano-copolymers.

\subsection{Preparation of latex paints formulations}

Evaluation of the novel high solid content nano emulsion polymers(St-EHA) co-polymers latex as a binder in waterborne House-hold paints was carried out. In order to obtain latex paints a high-speed disperser (dissolver 492- 
Table 10. paint formulation n low PVC

\begin{tabular}{|c|c|c|}
\hline Raw materials & & Low PVC \\
\hline Water & & 24.6 \\
\hline Sodium TetraPyroPhosphat & Wetting agent & 0.1 \\
\hline biocide & & 0.25 \\
\hline Hydroxy Ethyl Cellulose & Thickening agent & 0.2 \\
\hline ammonium salt poly acrylate & Disperse agent & 1 \\
\hline antifoam & & 0.6 \\
\hline $\mathrm{TiO}_{2}$ & & 23 \\
\hline hydrous kaolin & & 2.5 \\
\hline Prepared nano-copolymers & & 40 \\
\hline Texanol ester alchol & Coalescing agent & 1 \\
\hline Mono ethylene glycol & & 1 \\
\hline Opeque Polymer & & 5 \\
\hline Assosiative thickner HASE & & 0.65 \\
\hline Ammonia & & 0.1 \\
\hline Total & & 100 \\
\hline Specific gravity & & $1.2 \mathrm{gm} / \mathrm{cm} 3$ \\
\hline Solid content & & $48 \% \pm 2$ \\
\hline Viscosity KU/ 25C & & 100 to 110 \\
\hline Raw materials & & Low PVC \\
\hline
\end{tabular}

from ERICHSEN GmbH). All the amount of water determined in the formulation was added where the dispersing and cellulose thickener had been previously added. The disperser speed was increased up to $1000 \mathrm{rpm}$. After that, the remaining pigments and filler were selectively added. Finally, the disperser speed was decreased and the latex dispersion, co solvent, and acrylic thickener were added slowly to obtain full formulation homogenization, these procedure was represented in Fig. 9. and all the ingredients of the paint formulation recorded in Table 10.

4.2. Gloss, washabilty and viscosity of the prepared paint based on the nanocopolymers as a binder.

The samples of the prepared nanocopolymers were applied in emulsion paint formulations as a binder and evaluated, to compare with commercial reference sample Arakril ADC 750. The obtained results of wet scrub resistance test of the emulsion paint based on the nano-copolymers as a binder showed improved and higher valuables more than commercial reference sample (Arakril
ADC 750), also the gloss was improved. The data are shown in Table 11.

Table 11. Gloss and washabilty of the coating film based on the new prepared binder (nanocopolymers

\begin{tabular}{|l|c|c|c|}
\hline $\begin{array}{l}\text { Samples } \\
\text { Test }\end{array}$ & B & A & $\begin{array}{c}\text { ADC } \\
\mathbf{7 5 0}\end{array}$ \\
\hline Gloss & 44 & 30 & 37 \\
\hline Washablity & $>5000$ & 3500 & 3200 \\
\hline
\end{tabular}

4.2.1. Viscosity of the emulsion paints formulation based on the prepared nanocopolymer as a binder.

A paint formulation comprises a mixture of different components held in equilibrium with each other by the interaction - physically or chemically - of these components. These components can be categorized into different classes of raw materials. These include the dispersant, surfactant, pigments, latex and biocides. The thickening efficiency of the associative thickeners is impacted by the choice of some of these raw materials. In low PVC formula we get different viscosity for each 
sample, the low particle size give high viscosity Table.12. The associative thickener associates with the latex particle to form a network resulting in viscosity build. The choice of latex used in a paint formulation could have an impact on the thickening efficiency of associative thickeners. There are different classes of latexes used in paint formulation. Latexes with smaller particle size and therefore higher surface area will possess a larger number of association sites and give high viscosity paint more than latex has large particle size. When the Reholate associative thickeners are added to coating formulation, they organized into micelles and interact with other component in the formulation. Most important are the interaction between the hydrophobic units and the binder surface [35].this is not chemical reaction but a temporary adsorption and is responsible for the rheological activity. In water alone they give little structure until their micelles start to link (Fig.9).

\section{CONCLUSION.}

The current study aimed to develop latex with good properties in coating applications. The prepared polymers have a proper $T g$ to improved dry latex film properties. Prepared nano-copolymers were confirmed by IR, GPC, thermal analysis (TGA, DTGA and DSC), Zeta potential and TEM. Preparation of nanocopolymers were depend on different anionic surfactant (texapone and Desponil LDBS 25). Using these different surfactants in the experiments provided particles stability throughout the reaction. So, the effect of the emulsifier concentrations on final conversion of monomer to polymer was studied. It was found out that the final conversion of monomer to polymer increased with increasing emulsifier concentrations. The prepared (St /2EHA) nano copolymers were applied as a binder for waterborne house-hold paints and it was found out that the investigated paint films had good mechanical properties. Therefore, the prepared nano copolymers are recommended for application on waterborne paints for exterior

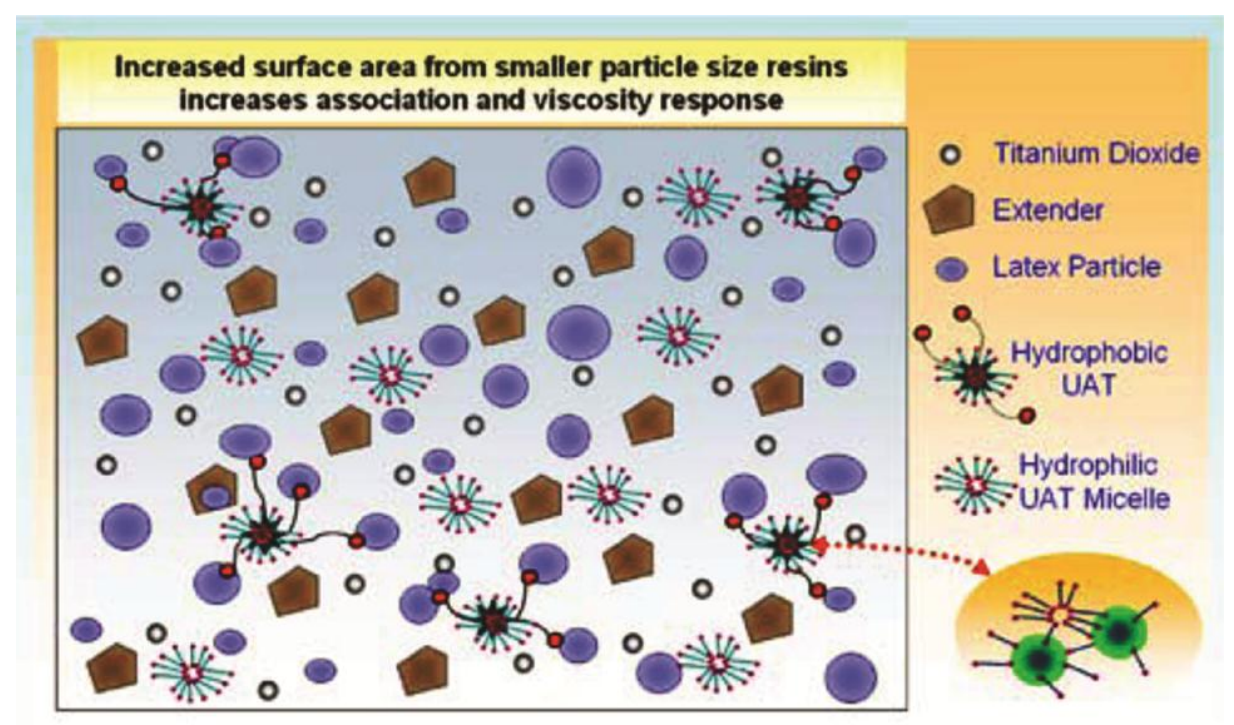

Fig.9. Reohlat thickener with paint ingredients.

Table.12. viscosity of low PVC formula based on the new prepared copolymers

\begin{tabular}{|ll|}
\hline Latex code & Viscosity KU \\
\hline A & 100 \\
B $~$ & 110 \\
ADC 750 & 105 \\
\hline
\end{tabular}


and interior house-hold walls. All prepared latex can be a future key ingredient in formulating high quality paints.

\section{ACKNOWLEDGEMENTS.}

We would like to express sincere gratitude to Egyptian British Company for chemicals and polymers, 6.October, Egypt. For research support through the chemicals and equipment's.

\section{REFERENCES}

1. K.K. Jena, R. Narayan, K.V.S.N. Raju, New high performance waterborne organic - inorganic hybrid materials from UV curing, Prog. Org. Coat. 76 (2013) 1418-1424.

2. J. Gao, H. Lv, X. Zhang, H. Zhao, Synthesis and properties of waterborne epoxy acrylate nanocomposite coating modified by MAPPOSS, Prog. Org. Coat. 76 (2013).1477-1483

3. V. Landry, P. Blanchet, wethering resistance of opaque PVDF-acrylic coating applied on wood substrateProg. Org. Coat. 75 (2012) 494-501.

4. F. Abd El-Monem., , A.I. Hussain.,H.A ELShahat. Nashy., H. Abd El-Wahhab., , A. M. Naser " Nano-emulsion based on acrylic acid ester co-polymer derivatives as an efficient pretanning agent for buffalo hide" Arabian Journal of Chemistry Received 1 March 2014; accepted 30 May 2014 article in press.

5. J. Hu, M. Chen, L. Wu, Organic-inorganic nanocomposites synthesized via miniemulsion polymerization, Polym. Chem. 2 (2011) 760772.

6. D. Qi, Y. Bao, Z. Weng, Z. Huang, Preparation of acrylate polymer/silica nanocomposite particles with high silica encapsulation efficiency via miniemulsion polymerization, Polymer (Guildf.) 47 (2006) 4622-4629.

7. C.S. Chern,( Emulsion polymerization mechanisms and kinetics), Prog. Polym. Sci. 31 (2006) 443-486.

8. Nianwei, Y., Keqiang, C., Wei, K. (2006) Ultrason. Sonochem., 13: 345-351.

9. H. M. El-Sherif, A. M. Nasser, A.I. Hussin, H. Abd El-Wahab, M.B.M. Ghazy, A.E. Elsayed""Novel Recycled Brown Paper Coatings" Egypt. J. Chem V 59, NO 6, (2017) pp 1-18

10. M.J.Unzue, Schoonbrood, H. A. S.,J.M Asua, A.M.Go ni, Sherrington, D. C., St€ahler, K., Goebel, K. H., Tauer, K., Sj€oberg, M.,
Holmberg, K. (1997) J. Appl. Polym. Sci., 66 (9): 1803-1820.

11. A. M. Nasser , H. Abd El-Wahab, M. Abd ElFattah, Abdelzaher E. A. Mostafa, and Ahmed G. Sakr "Preparation and characterization of modified reclaimed asphalt by using styrene butyl acrylate nanoemulsion copolymer" Egypt. J. Chem. Vol. 61, No.2, pp. 280 - 290 (2018)

12. H. M. El-Sherif, A. M. Nasser, A.I. Hussin, H. Abd El-Wahab, M.B.M. Ghazy, A.E. Elsayed "Nano Emulsion Binders for Paper Coating Synthesis and Application" accepted on the Journal of Macromolecular Science PAC. March, V 54, NO 5, (2017) pp 271 -287.

13. Y. Shi, G. Shan, Y. Shang, Role of Poly(ethylene glycol) in Surfactant-Free Emulsion Polymerization of Styrene and Methyl Methacrylate (2013) Langmuir, 29 (9): 3024-3033.

14. M.M. Bukhari, A.A. Alyan, S.F. Hegazi,(nano emulsion(miniemulsion) copolymerization of styrene with methyl meth acrylate using hexadecane and dodecyl mercaptan cosurfactants. (2014) Jazan Sci. J., 4 (1): 30-45.

15. S. Pashaei, A.A.Sayed .( Thermal degradation kinetics of polyurethane/organically modified montmorillonite clay nano-composites by TGA) Journal of Macromolecul. Sci. Chem.2010, 47 (8): 777-783.

16. P.A. Lovell, M.S. El-Aasser, Emulsion Polymerization and Emulsion Polymers, john Wiley \& Sons Ltd, Chichester, 1997.

17. K. Zhao, P. Sun, D. Liu, G. Dai.( The formation mechanism of poly(vinyl acetate)/ poly(butyl acrylate) core/shell latex in two-stage seeded semi-continuous starved emulsion polymerization process,) European Polymer Journal, vol. 40, no. 1, pp. 89-96, 2004

18. M. Okubo, Polymer particles, Springer Berlin Heidelberg: New York,2005.

19. W. Chen, W. Zhu, M. Song, S. Sun, B. Chen, Y.H. Adler. (2005) Macromol Mater. Eng., 290: 669-674.

20. D.Cangialosi, A. Alegría, and J.Colmenero. (2016): Effect of nanostructure on the thermal glass transition and physical aging in polymer materials, Progress in Polymer Science 54-55 128-147.

21. H.Ismail, Z. Ahmad, and F.W.Yew. (2011): "Effect of Monomer Composition on Adhesive Performance for Waterborne Acrylic PressureSensitive Adhesives". Journal of Physical Science, Vol. 22 (2), 51-63. 
22. Lee DI. (2005): "The effects of latex coalescence and interfacial cross linking on the mechanical properties of latex films. Polymer; 46: 1287-1293.

23. P.R.Guevin , Jr, (1995): "Hardness in Paint and Coating Testing Manual", 14th edition, ed. J.V. Koleske, ASTM, Philadelphia, PA, Chapter 48.

24. A. Achouri, Y. Zamani \& Joyce Irene Boye (2012): "Stability and Physical Properties of Emulsions Prepared with and without Soy Proteins", Journal of Food Research Vol. 1, No. 1, 254 ISSN 1927-0887 E-ISSN 1927-0895

25. C.Y. Kan, D.S. Liu, X.Z. Kong, X.L. Zhu, Study on the preparation and properties of styrene-butyl acrylate-silicone copolymer lattices, J. Appl. Polym. Sci. 82 (2001) 3194 3200.

26. S.Q. Huang, Z.S. Xu, H. Peng, S.Y. Cheng, Properties of PHMS-g-P[butylacrylate (BA)Nhydroxylmethyl acrylamide (NMA)] graft copolymer emulsions, J. Appl. Polym. Sci. 71 (1999) 2209-2217.

27. S.F. Yang, P.T. Xiong, T. Gong, D.P. Lu, R. Guan, St-BA copolymer emulsions (BA)Nhydroxylmethyl acrylamide (NMA)] graft copolymer emulsions, J. Appl. Polym. Sci. 71 (1999) 2209-2217.

28. W.D. He, C.T. Cao, C.Y. Pan, Formation mechanism of silicone rubber particles With core-shell structure by seeded emulsion polymerization, J. Appl. Polym. Sci. 61 (1996) 383-388.

29. T.Y. Cao, Q.P. Liu, J.S. Hu, Preparation, Properties and Applications of Polymer Latexes, Chemical Industrial Press, Beijing, 1997.

30. A.P. King, H. Naidus, The relationship between emulsion freeze-thaw stability and polymer glass transition temperature, J. Polym. Sci. Part C 27 (1969) 311-319.

31.X. Z. Kong, X. Zhu, X. Jiang, ,X. Li, preparation and full characterization of cationic latex of styrene butyl acrylate polymer) (2009) Polymer, 50: 4220-4227.

32.A.I. Hussain, , H.E. Nasr, (The Role of Carboxylic Acid on the Characterization and Evaluation Seed Emulsion of Styrene/ Butyl Acrylate Copolymers Lattices as Paint (2010) Nature Sci., 8 (8): 94-103.

33. Elementis Specialties, "Rheology Handbook: 30th Edition”, pp.14-21, 2008 